\title{
On the Revolution and Trend of Modern Men's wear
}

\author{
Ding Ying \\ Jiangxi Institute of Fashion Technology,Department of Dress Design and Engineering \\ Jiangxi Institute of Fashion Technology, JF \\ Nanchang, Jiangxi \\ e-mail: 185503378@qq.com
}

Keywords: Modern; Men's wearing; Consuming; Revolution; Trend

\begin{abstract}
Costumes are the special fruit of the human, which is the crystal of human material civilization and embodied the connotation of spiritual civilization. Fashion clothes are a surface decoration which is usually considered to be the masks used to cover up the bodies or the facts. The way of wearing can be considered as a construction or a positive process and technology method to show up what they need and want. Modern men are not content with the merely warming and comfortability of the clothes, and begin to pursuit the creation and fashion. The conclusion can be drawn from the fashion show. With the development of the social, men's wearing will have huge space. Men's wearing is not only limited to the official clothes for showing. The men's wearing is changing, developing and progressing. The men's wearing does not only stand for the power and the status, but also the ability of consuming and the strength to choose in development. The popularity of men's wearing shows the balance structure and social phenomenon.

The clothes, as a special production of the society, are appearing according to the development of the society. The clothes are a symbol and a sign. It stands for the political and social status, let everybody behave properly and abide by the social rule. Therefore, the Emperors had their special clothes since ancient times and created the clothes rule. To some extent, the political order was built according to the development of the clothes. So, clothes is a part of politics, and the importance of clothes far exceeds the status of clothes in the society.

Costumes are the special products of human, which was the crystal of human material civilization and embodied the connotation of spiritual civilization. The human society had evolved from the obscuration to the civilization for hundreds of thousands of years. From the beginning of the clothes, living customs, aesthetic interest, color hobby, cultural mentality and religion idea are all embodied in clothes to build the spiritual civilization connotation of the clothes culture. Today, clothes are not only used to keep warm or comfort, but also pursuit the technology measures to embody the relationship between the body and the living environment and the space between the body and the body activities. In other words, the clothes reflect the personal habituation. The habituation also brings expectation, rule and technology. As it is known, there are all necessary living conditions under the concert environment to the human. From this aspect, the body is built through two meaning. One is built by the technology; another is built through the habit manifestation mode to show the concert livings. The technology of body fashion is an obvious way of culture introduction. People usually show themselves to the society through the decoration to the body, show their behavior rule through the fashion and bring a new visage for them which does not cover natural body or real characteristic but built personality positively.

$21^{\text {st }}$ century is a century with the creation; people have had new cognitions to the creation and the development of the clothes as well as the time to discuss the development of the economic and culture. The development of the information technology had brought the explosive changes to the world. Of course, it also brought lots of difficulties for predicting the future events. Just because of that, fashion has become a civilization technology. Fashion is a method of embodying culture. Through the embodying, the single and the group keep the same pace with the vision around the culture. Recent years, the fashion shows in the west trend that fashion is a common phenomenon in
\end{abstract}


daily livings, not limited to the top fashion and upper class and the character is not limited to the latter. Wearing is a method to show people themselves through the social touch. Some parts of the body can be performed well through the decision to the clothes or the limit of the action. The clothes mirror people's characters. From this point, the clothes have become a parameter of people's living environment. The elite fashion in west is a form used to decorate the body.

The fashion was thought to be the proper civilization expression of the west culture in the west fashion system. The contradiction doing in the west fashion for many years reflects the insisting to the civilization through the exposing and the covering. On the whole, the fashion shows the characters of the social body through the clothes, the ornament, and other rules. The fashion reflects the social behavior from the whole view. Of course, the fashion was affected by the social environment. In other words, the fashion's development was limited to the social environment. There is no doubt that the fashion reflects the era peculiarities, however, the body limited to the fashion is always changing. Just because of that, its change helps the creation of the fashion design. People may have the ambiguous attitude towards the fashion, but the importance of the fashion is sure. There is an old saying in China: Fine feathers make fine birds, which is suitable to people today.

Up to today, people do not limit to the record of the history of the fashion and the west clothes system, and they put their attention to the top fashion which are being designed by the elite designer. Make a long story short; the fashion is an action of putting the popular style or the form to the person; is a forced action with full of arbitrariness and avoiding other forms or styles. The fashion system in the west was thought to have close relationship with the right. Of course, the opinion was suitable to other fashion system. That's because all fashion system contain the politic in this environment. Until today, the development of the fashion is confused and changeable. However, it is what people want to discuss here. What people want to discuss is the problem of the fashion of the men's wear. Much information has showed that the fashion belongs to the women only. Towards the view, the author does not agree with it, the author thinks the fashion not only belongs to the women, but also the men.

When the women are pursuing the fashion, the men are also affected. From the style of the Rococo in $18^{\text {th }}$ century, many men began to worn the tight clothes by the affect of the women. It is a great surprise to the east (such as Fig.1). From the objective aspect, that is not the essential difference between the man and the women. It is a concert history and culture phenomenon. With the change of the clothing rules, the fashion began to distinguish the sex. Just in this process, the women undertake the task to pursue the fashion. So, the view about the men clothes had become negative. The negative views as follows: the men have no fashion; the norm of men wearing is fitting and comfort, not pursuing the special style. The women purchase clothes for the men and decorate them. Most men didn't experience the cheat of pursing fashion. In other words, even people didn't deny the exist of the men fashion, they ignore the exist of the men fashion. From another aspect, people have different and distinct views towards the male and the clothes. As it is known to all, they draw the conclusion because they are affected by the common customs. There is no doubt that there are difference and connection. Modern women decorate themselves to be admired by the image of emphasizing the wearing rule; however, the men clothes emphasized the initiative of the man, especially in the vocational and social status. 


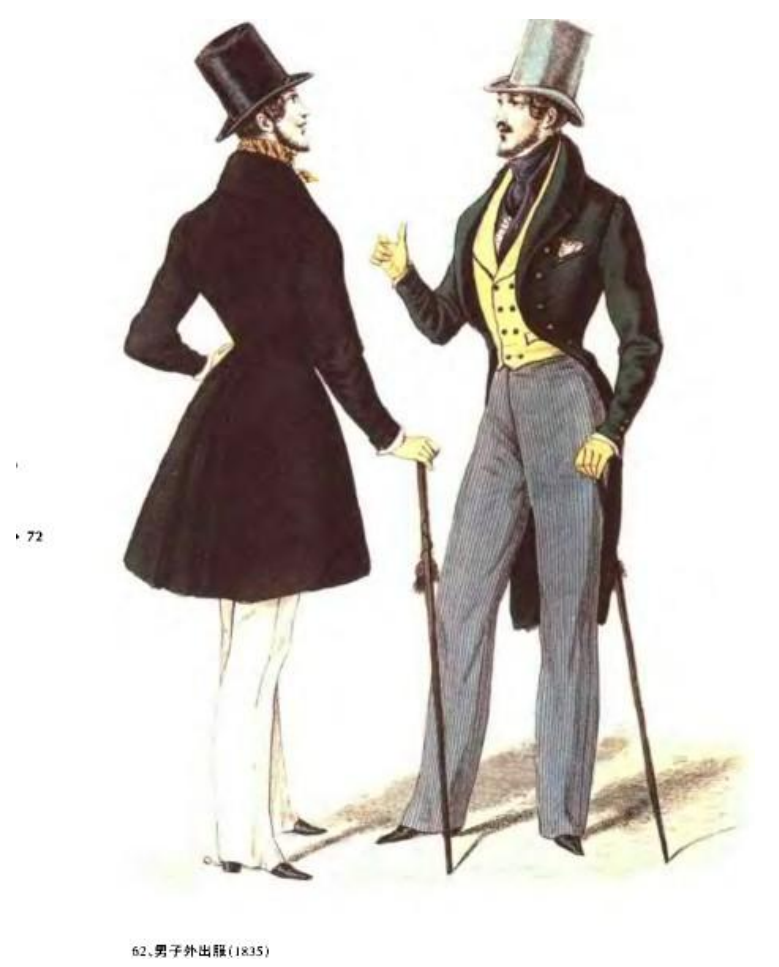

Figure 1.

After 1960s, the man fashion was concerned by the people again. Deeply speaking, after the post-industrial society, people began to challenge the status of the men leader. With the entering vocational market of the women, they undertake the social responsibility and challenge the right of the men. Therefore, the men accept new clothes rule. They change their morals and authorities image through the way of flirtatious and narcissistic wearing.

During the 1980s and the 1990s, much discussion about the man fashion appeared. The main idea of the discussion is that the men have given up their attitude towards the clothes. And this attitude was just attracted by the fashion designer and some clothes store. There is a popular view that the men have realized from the situation of not interest towards the clothes and discovered the significance of the clothes. However, people looked back the history, not mention to the across-culture. And it will be found that it is a skeptical saying. The man fashion has a long history and has more strict rules and prohibitions than women fashion.

People do not only find some changing disciplinary in men fashion, but also the adaption to the women fashion in the change. Of course, it can be seen that men's choice to clothes is less than ever before which makes them have less choice and they wore similar clothes. The traditional men boycotted the fashion or accept the main clothes. On the contrary, the special fashion characterized the personality was limited to the gentleman, playboy, singer and film stars, and the national minority. The center of heterosexuality relationship and the form of man idea expression usually sneered at the main moral of the male. The man idea was expressed through the clothes and the style with politic meaning. Modern men expect to their male image through their right. To some men, it is an important thing. To other people, it is of little importance; at least it is so from the surface.

Decoration and showing body are appearing gradually in the $20^{\text {th }}$, and they were ambivalent with lust and terror. The man myth of no decoration covered the contradiction with the social body. In the process of Euro-industrial, the men paid attention to the vocation, because the vocation would bring social status and social right, which will affect their living method. On the contrary, the women in that time addicted into the fashion store, they controlled and led the style of the clothes. In this situation, the men realized that they should abandon the laziness and the luxury, to give up the clothes owned by the noble and the living rule. What they wore showed that they have become new industrial person. When the men were working hard in the politic and economic aspect, the women 
who addicted into the fashion were endowed to show the status of men using clothes and behavior. It can be known that the men were in a certain condition of obscuration. They had no real idea towards the fashion. Some phenomenon which is obvious is seen in non-man circle, especially the fashion with the female characters. They were not absolute man fashion. Their real fashion meaning was affected by the post-industrialization. The fashion idea came from the social meaning of the vocation and the status. Of course, it is a symbol of the time, further; it is a real portrayal of the right and the status.

Many people had the same attitude as the playboy whose situation was affected by the economic situation and other real situation. Besides, they had the fetter of the traditional aesthetic view. On the whole, the conservation and the resistance to the change were the main characters in the $19^{\text {th }}$. The reason was simple, that people sneered at the excessive decoration in the man clothes. They adopted the way of setting up the positive model and sneering at the unhealthy phenomenon. The man fashion store provides new clothes for the consumer, and become the resource of related knowledge. The tailors and the column of some magazines about the man and other etiquette booklet all told the man how to put themselves into the gentleman (such as Fig. 2).

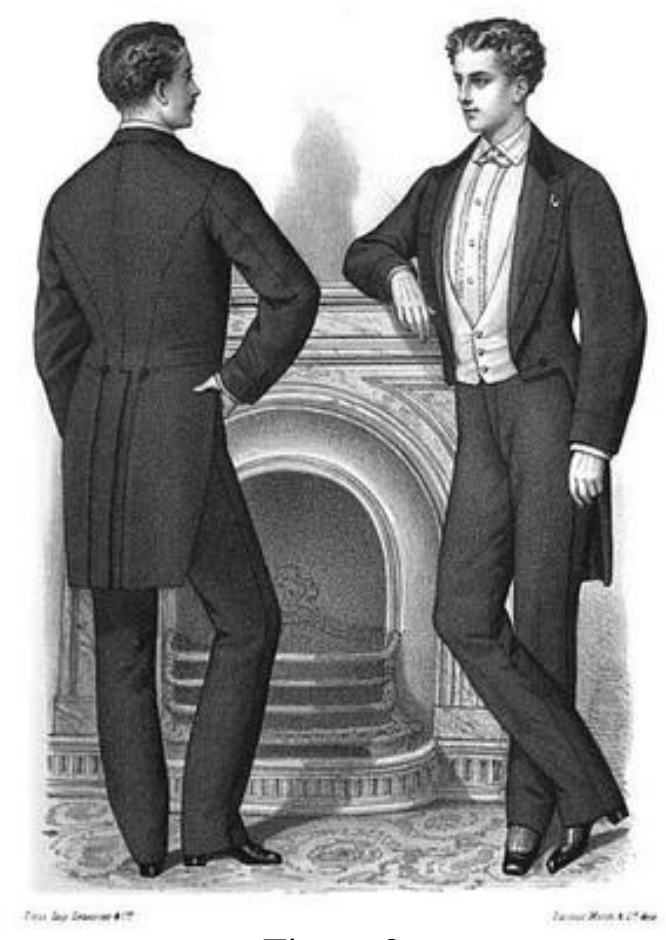

Figure 2.

With the change of the idea that more and more men do not need to move when they work, especially in the office. Different vocation needs people to wear different clothes, therefore, the office clothes are obtaining more and more functions, and become the main clothes for the white-collar worker. In some vocation, such as the police, the army and the doctors, they begin to show their authority through their uniform. Among the blue-collar workers, the coarse cloth and the jumpsuit are replacing the suit and becoming the main uniform. Besides, people are using different colors to describe the relationship between the clothes and the vocation. The people who work in the laboratory and under the sun wear the clothes of the white; the people whose works have relationship with the engineering wear the clothes of the blue; the people who operate the machines wear the clothes of the yellow.

The suit was the main clothes for the men in the $20^{\text {th }}$ century. People had ever challenged the confined suit of the men. The organization of the creation of the clothes built from 1929 to 1937 showed the challenge. Of course, the organizations were built in Newland, India, China, Australian, South Africa, Egypt, Costa Rica, Austria, America and Canada. The creation sports expected to 
cancel the suit and the shirt which were thought to be harmful to the body of the man and the action. The creation sports reflected that the Europe would not the center of the fashion. The center of the fashion did not only exist in London and Paris. In other countries, due to the different climate and working conditions, people must wear different clothes to adapt to the environment. As it is known to all, America has entered the front in the clothes like other things and other countries follow the example of America, which has become a great challenge to the European market.

Though the creation sport was not exist for a long time, it had a great effect towards the swimsuit of the men, casual outdoors fashion and sportswear. It is hardly known that the change had begun before or just under the acceleration of the sport. The sport had provided the causal and light clothes for the people. Such as the short trousers and the shirts what people wore when playing the tennis which proved that it was a radical sport. Later, about the debate and the resistance of the knee and the leg with full of down opened to the public. At last, the audacious clothes which were made from the light material were accepted by the people. The tropical travel clothes fit for the climate of the Asian, which melt the characters of the suit, the short trousers and the army clothes. Up to today, the clothes had a long history. This kind of clothes had its status, especially in the post-colonial country. To sum up, the clothes reform promoted the production of the special sports clothes and the casual clothes.

However, the creation sports had no much effect towards the office clothes. The design of the man suit had experienced many changes in the $20^{\text {th }}$ century. In last century, the man suit looked like oval, with the narrow shoulder, opening lapel, broad ass and parochial trousers legs. From 1926 to 1939, a series of changes in the collar made the oval into the inverted triangle. During this term, the man fashion was classified by the point of the consumer. For example, the Seal Company in the America classified the consumers into the handsome consumer area, accepted higher education consumer area or area with the consciousness of the man fashion, the merchant and the conservatives towards the clothes. This classification seems to be ridiculous, but it panders to the time development and the progress. Further, it promoted and pandered the reform of the fashion again. The division is more and more thin, more and more elaborate, and the rank is more and more strong. It is obvious in the change of the style.

In the past, a man would be denied if he ignored his wearing. In the concept of the silent fashion, it was not accepted really by the people. Men did not wear the sexual clothes due to the terror and the terror psychology, and they did not attend some actives to show their features, containing shopping, the reading romantic novel, enjoying the window display, the fashion show and the fashion magazine. The men emphasized the strict utilitarianism and refused the action of sissy.

Until 1960, some designers paid attention to that. They thought that the men clothes might become the fashion. After that, the changing were appearing, men clothes were not cut and made just by the tailor. People liked to wear the light and uncontained style clothes which could be matched through single or other accessories. And the suit was not the element parts of the man clothes. Under the effect of the film star, people paid more and more attention to the popular clothes. After that time, the casual clothes developed quickly (such as Fig. 3). The office clothes and the informal clothes were distinguished. The man, especially some young people, they behaved over cooking in the clothes in the 1960s. From 1970s to 1980s, on the whole, they became more and more bold. They had a bold try in the color, the style and the cutting. In a word, sometimes, the man had no rules to wear; they had no fashion or had no interest towards the fashion, which is doubtful, which is a culture deviation in the modern history. 


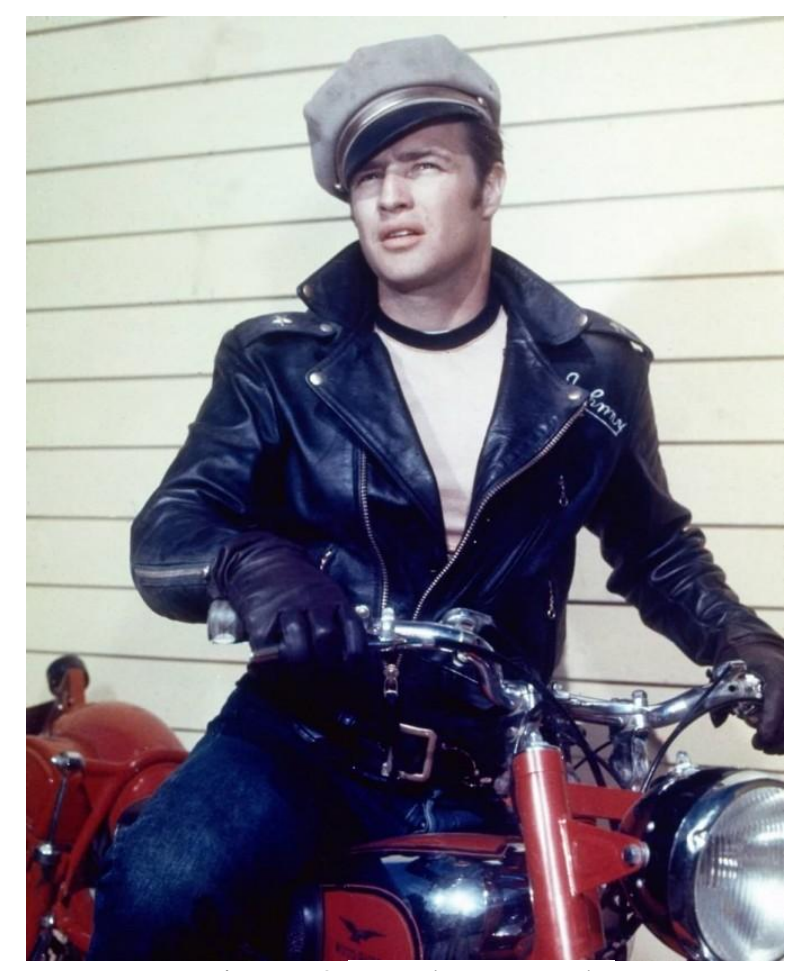

Figure 3. Marlon Brando

In the past 10 years, new type man, a new vocabulary appeared in the discussion of the man and the clothes. The new type man manifested many ideas: the idea of humanism; the model of the form defeating the content; a symbol of the legal consuming; A stratagem of persuading people to call and accept the change. The new type men contained its opponent, the old type man. The image came from the types as follows: the gentleman who behaved politely and had silent personality; the jeans and the combat hero stood for the strong, the independence and the silence; the lazy men pursuing function but not caring the speed and the style; the wayward and the ambitious male chauvinism. The ingredient could be found in the new type man, but they were all contradictory and had different man culture features. The appearing of the new type man was a reflection to the feminism and the women situation, and it was a new revalue to the man idea. The feminism led to the negation of the man and the criticism of the hard man image. The narcissism and the care towards other people had become the new elements of the man. The new type man image centered the man body and the sex feature, all of these had formed the image of the man. The new type man not only had the fashion consciousness, but also the consumer of pursuing positively self-feeling.

In the 1980s, the mass-media and the popular culture indicated the appearing of the flaunt men. This kind of men knew that their bodies were not only machine, but also had sex charm. However, the clothes and the match methods could add sex charm, though the clothes of the man seem conservative and mild comparing to the clothes of the women. Of course, the shirt, the coat, the trousers and the suit are the main clothes of the men. However, the cutting method, the color and the material could be used and chosen than ever before. The man fashion contains the casual clothes with the unique style, underwear and the special fashion. Some designers, such as Jean Paul Gaultier, George Alzheimer, John Galliano, Kenzo, Rei Kawakubo, Yohji Yamamoto, expanded the range of the man fashion through the extreme image design. Many designers designed clothes to stand for the clothes with the characters of the man and the woman and the characters of the only woman in 1960s and 1970s. The shirts and the trousers with soft material and smooth line are the examples of what they designed

At the same time, the women started to wear the shirt that belonged to the man before and the remade coat and the underwear of the man. The designer Romeo Gigli admitted that many women like to wear the long trousers and the man shirt. Therefore, he designed some clothes that could be 
worn by the man and the woman. Jean Paul Gaultier used lace and silk limited to the female material and the leather clothes with the sex meaning and the skirt with the man to display the extreme of the top man fashion. His design led to a great debate due to the characters of the women and the challenge to the man ideas. From the point of the history and the culture, the skirt was not fancy dress in the man clothes, but a common men clothes. Such as the skirt in the country of Roman, Arab and Greece; the short skirt, the Malay apron in England; the kimono and the shepherd's smock.

The change of the man rule may have other meaning. The frivolous man clothes and their ignoring towards the body and the image reflected the change of the status of the man. Many men, just like the women, undertake the household. There were some men students who could not find suitable job after graduate. Therefore, the clothes of the man had to be changed and remade according to the situation. The acceptance to the plain clothes affected the office clothes. Therefore, the plain clothes challenged to the jacket, the loose clothes, the shirt and the formal office clothes. On the other hand, the woman obtained their job with high social status and salary. The factors of the men were added into the women clothes. Accordingly, the wearing of the middle class and the top society could not distinguish their status. The clothes which keep the distinction of the status and the sex are still existing. A great amount man and woman opposed the doing of decorating and showing the body of the man publicly. The showing men would not come again in a short time.

In fact, in the process of men clothes development, it does not only stand for the right and the status, but also the power of the consuming, the strength of choosing in the development. Further, the fashion is a body technology that is marked by the social behavior. The technology will not be forced by the other forces from the top to the bottom. It incarnated the ability of the group and the single. During the process of pursuing fashion to imitate, people formed the regular technology through the action, behavior and body language, which is a common measure embodying through the culture.

The rising of the man fashion showed the balance construction, which broke the idea that the fashion only existed in the woman fashion and ignored the need of the man. The development of the society and the city need clothes to support, need fashion to balance, which is the combination of $21^{\text {st }}$ century and the need of the society.

\section{REFERENCES}

[1] Jennifer Craigslist(America), the Features of the Fashion, Central Compilation and Translation Press,Mar. 2003.

[2] Masayuki Kurokawa(Japan), the Pattern of the Century Design, Shanghai people's Fine Arts publishing House.Aug. 2003

[3] Bao Mingxin, Cao Chuang, the Post-Modern Fashion of the overseas.Aug. 2001.

[4] Chen Jianhui, Zhang Sicong, the West Man Fashion Design with the Femininity in the Post-Modern. Decoration,Feb.2006.

[5] Wu Zhiming, Yang Juan, On the Phenomenon of the Modern Man Fashion into the Femininity from the Point of the Aesthetic. Progress in Textile.Feb. 2006.

[6] Lu Yan. The living Style of the Blue Collar and the New Concept to the Market of the Man Fashion. Sichuang Silk, Jun.2014.

[7] Liu Shuli, the Explanation to the Trend of the new type Man Fashion. Progress in Textile. Jun.2014.

[8] Qian Mengyao, the History and Modern Transformation of the West man Fashion Design. 《Journal of Nanjing Arts Institute(Fine Arts \& Design)》, Mar.2015.

[9] Feng Lingling, on the Research to the Creation in the Man Fashion Design. Feb.2014. 
[10] Zhou Wenjie, the Art of the Man Fashion Design. Chemical Industry Press. Sep.2013.

[11] Yuan Ze, the History of the Foreign Countries. Xinan Normal University Press. Sep.2009. 